\title{
Osteopoikilosis in the pelvic region
}

\author{
Choon-Hoon Hii MD, Che-Kim Tan MD
}

See related practice articles by Di Primio, page 456 and by Padín-Paz and Díaz-Peromingo, page 461

Competing interests: None declared.

This article has been peer reviewed.

\section{Correspondence to:}

Dr. Che-Kim Tan,

chekim.tan@gmail.com

Affiliations: From the Emergency Department (Hii), Kuang Tien General Hospital; and the Department of Intensive Care Medicine (Tan), Chi-Mei Medical Center, Taiwan

CMAJ 2011. DOI:10.1503 /cmaj.082095

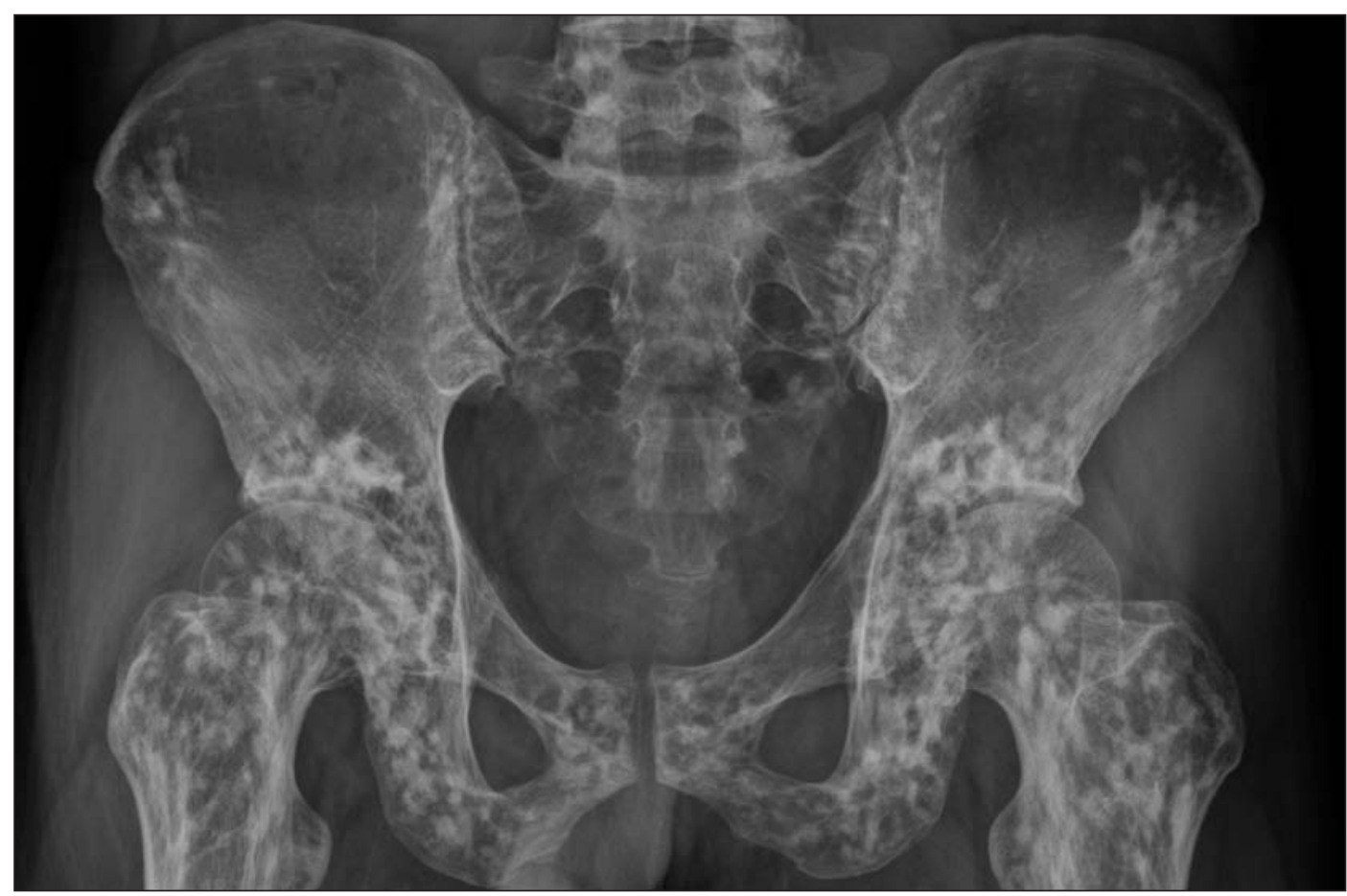

Figure 1: Pelvic radiograph showing small, sclerotic, round opacities distributed symmetrically along the sacroiliac joints, pubic symphysis, acetabulum of the pelvis and femoral heads.

A 28-year-old man presented with epigastric pain after alcohol intake. His physical examination was unremarkable. Abdominal radiography showed small, round, sclerotic opacities distributed symmetrically along the sacroiliac joints, pubic symphy sis, acetabulum of the pelvis and the femoral heads (Figure 1).

These characteristic bony lesions suggested a diagnosis of osteopoikilosis. The differential diagnosis includes osteoblastic metastasis, mastocytosis and tuberous sclerosis. ${ }^{1}$

A normal complete blood count and normal test results for C-reactive protein, rheumatoid factor, calcium, phosphate, alkaline phosphatase, parathyroid hormone, Bence Jones protein, tumour markers, and thyroid, renal and liver function, as well as a normal radionuclide bone scan, further supported the diagnosis of osteopoikilosis. Further radiologic examination showed similar lesions on the bones of his hands and around the glenoid of the scapula (Appendix 1, available at www.cmaj.ca/cgi /content/full/cmaj.082095/DC1). Our patient remained symptom-free with no change to his sclerotic lesions after one year of follow-up.

\section{Reference}

1. Di Primio G. Benign spotted bones: a diagnostic dilemma. CMAJ 2011;183:456-9. 